(C) 2020, The Authors. Published by FASS Inc. and Elsevier Inc. on behalf of the American Dairy Science Association ${ }^{\circledR}$. This is an open access article under the CC BY-NC-ND license (http://creativecommons.org/licenses/by-nc-nd/4.0/).

\title{
Development of feed composition tables using a statistical screening procedure
}

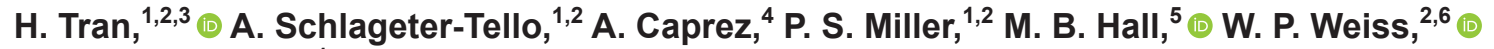 \\ and P. J. Kononoff ${ }^{1 *}$ (1) \\ ${ }^{1}$ Department of Animal Science, University of Nebraska-Lincoln, Lincoln 68583 \\ ${ }^{2}$ National Animal Nutrition Program, University of Kentucky, Lexington 40546 \\ ${ }^{3}$ Land O'Lakes Inc., Arden Hills, MN 55126 \\ ${ }^{4}$ Holland Computer Center, University of Nebraska-Lincoln, Lincoln, 68588 \\ ${ }^{5}$ US Dairy Forage Research Center, Madison, WI 53706 \\ ${ }^{6}$ Department of Animal Sciences, The Ohio State University, Wooster 43210
}

\begin{abstract}
Millions of feed composition records generated annually by testing laboratories are valuable assets that can be used to benefit the animal nutrition community. However, it is challenging to manage, handle, and process feed composition data that originate from multiple sources, lack standardized feed names, and contain outliers. Efficient methods that consolidate and screen such data are needed to develop feed composition databases with accurate means and standard deviations (SD). Considering the interest of the animal science community in data management and the importance of feed composition tables for the animal industry, the objective was to develop a set of procedures to construct accurate feed composition tables from large data sets. A published statistical procedure, designed to screen feed composition data, was employed, modified, and programmed to operate using Python and SAS. The 2.76 million data received from 4 commercial feed testing laboratories were used to develop procedures and to construct tables summarizing feed composition. Briefly, feed names and nutrients across laboratories were standardized, and erroneous and duplicated records were removed. Histogram, univariate, and principal component analyses were used to identify and remove outliers having key nutrients outside of the mean $\pm 3.5 \mathrm{SD}$. Clustering procedures identified subgroups of feeds within a large data set. Aside from the clustering step that was programmed in Python to automatically execute in SAS, all steps were programmed and automatically conducted using Python followed by a manual evaluation of the resulting mean Pearson correlation matrices of clusters. The input data set contained 42, 94, 162,
\end{abstract}

Received March 28, 2019.

Accepted November 14, 2019.

*Corresponding author: pkononoff2@unl.edu and 270 feeds from 4 laboratories and comprised 25 to 30 nutrients. The final database included 174 feeds and 1.48 million records. The developed procedures effectively classified by-products (e.g., distillers grains and solubles as low or high fat), forages (e.g., legume or grass-legume mixture by maturity), and oilseeds versus meal (e.g., soybeans as whole raw seeds vs. soybean meal expellers or solvent extracted) into distinct subpopulations. Results from these analyses suggest that the procedure can provide a robust tool to construct and update large feed data sets. This approach can also be used by commercial laboratories, feed manufacturers, animal producers, and other professionals to process feed composition data sets and update feed libraries.

Key words: clustering, principal component analysis, database, nutrient

\section{INTRODUCTION}

The process of diet formulation for livestock species requires an accurate knowledge of the nutrient composition of feedstuffs. From estimates of nutrient composition, nutritionists are able to combine available feeds in an appropriate proportion to match nutritional requirements of animals. Although nutritionists routinely submit samples to commercial feed testing laboratories, they also often rely on feed composition tables to provide estimates of nutrient composition of feeds not commonly analyzed (Tedeschi et al., 2008). For example, due to the low variation in nutrient composition between batches, nutritionists routinely use tabular nutrient composition values for concentrate ingredients such as corn and soybean meal (St-Pierre and Weiss, 2015). Nutritionists also rely on feed composition tables to estimate concentrations for nutrients that are expensive to determine, such as amino acids and fatty acids. Finally, feed composition tables could be a source of 
estimates for variability in nutrient composition (i.e., SD). Knowing accurate estimates of nutrient variability would allow nutritionists to adjust safety factors (defined as offering excess of nutrients to minimize risks of deficiency associated with nutrient variability) to a minimum level, allowing formulation of more efficient rations (St-Pierre and Weiss, 2015). Accurate estimates of true nutrient variability are also needed for stochastic diet formulation methods (St. Pierre and Harvey, 1986 a,b,c)

The development of feed composition tables grew in extent and complexity in the 1950s, when the National Research Council (NRC; currently the US National Academies of Science, Engineering and Medicine, NASEM) published tables that contained data on the nutrient composition of different by-products (NRC, 1956) as well as cereals and forages (NRC, 1958). Over time, feed composition tables were expanded to include more feedstuffs, along with attempts to standardize nomenclature and updates with more accurate data (NRC, 1971, 1982). Currently, NRC/NASEM feed composition tables are commonly used globally for diet formulation (Thornton, 2010). Additionally, different countries have developed their own feed composition tables, assuming differences in nutrient composition due to geographic location. Some examples of such feed composition tables are those from France (Sauvant et al., 2004), the United Kingdom (Ministry of Agriculture, Fisheries and Food, 1992), and the Netherlands (Federatie Nederlandse Diervoederketen, 2016). Expansion and curation of feed composition tables and databases should be an ongoing processes.

Historically, feed composition tables such as those published by the poultry NRC (1994) and swine NRC (2012) industries are constructed from pre-existing data sets and data collected from scientific literature. These literature-based feed composition tables rely on small data sets using simple data management processes. Furthermore, collecting data from literature is a timeconsuming process, requiring review and extraction of data from a large number of publications, and the small sample size may result in inaccurate estimates of population parameters. An alternative approach was adopted by the dairy cattle NRC (2001) and beef cattle NASEM (2016) committees, which constructed feed composition tables using data provided by commercial laboratories. Feed composition tables based on data sets provided by commercial laboratories are constructed using large data sets containing thousands or even millions of data for every nutrient and feed. Use of large data sets should improve estimates of statistical parameters and ensure they are more representative of the population of feeds. However, it is difficult to process and manage large data. Additionally, file formats, data structure, and feed classifications differ among the feed testing laboratories. Managing such large databases requires computers with high processing power and software able to run automated procedures to consolidate files, to screen outlying observations and detect misclassified records.

Creation of large databases has provided a useful resource not only in animal nutrition but in a variety of applications such as genetics, animal health and environment, and others (Morota et al., 2018; Lokhorst et al., 2019). Thus, considering the increasing interest of the animal science community in big data management and the importance of feed composition tables for the dairy feed industry, the objective was to develop a set of procedures to efficiently construct accurate feed composition tables from large, messy data sets.

\section{MATERIALS AND METHODS}

\section{General Procedures, Data Collection, and Pre-Screening}

The statistical screening procedure to develop the feed composition tables consisted of 4 steps: (1) data set collection; (2) data pre-screening, aimed at assigning a standard nomenclature for data sets received from different sources; (3) automated statistical screening procedure, aimed at removing outliers and detecting clusters within larger data sets; and (4) data summary, to create final feed composition tables. A summary of the steps included in this process is illustrated in Figure 1.

In the fall of 2015, 4 commercial feed testing laboratories in the United States (Dairyland Laboratories, Arcadia, WI; Cumberland Valley Analytical Services, Waynesboro, PA; Rock River Laboratory Inc., Watertown, WI; and Dairy One, Ithaca, NY) were contacted, and feed analysis data were requested. Together these laboratories kindly provided a data set containing 2.82 million records (defined as an analysis of a single feed sample conducted by 1 laboratory) collected between 2011 and 2015, and delivered as .xlsx or .csv files.

The objective of the pre-screening process was to create standardized files to be used as the input data set for the automated statistical screening process (Figure 1). The first step within the pre-screening process was to remove feed records that could not be used in the final database. Unusable records included unidentified records, records with missing values for all nutrients, records referring to TMR, feed mixtures, commercial products, or mineral mixtures, and non-feed records such as water and manure. The second step in the pre-screening process was to standardize feed and nutrient names. In general, nomenclature for feeds was 

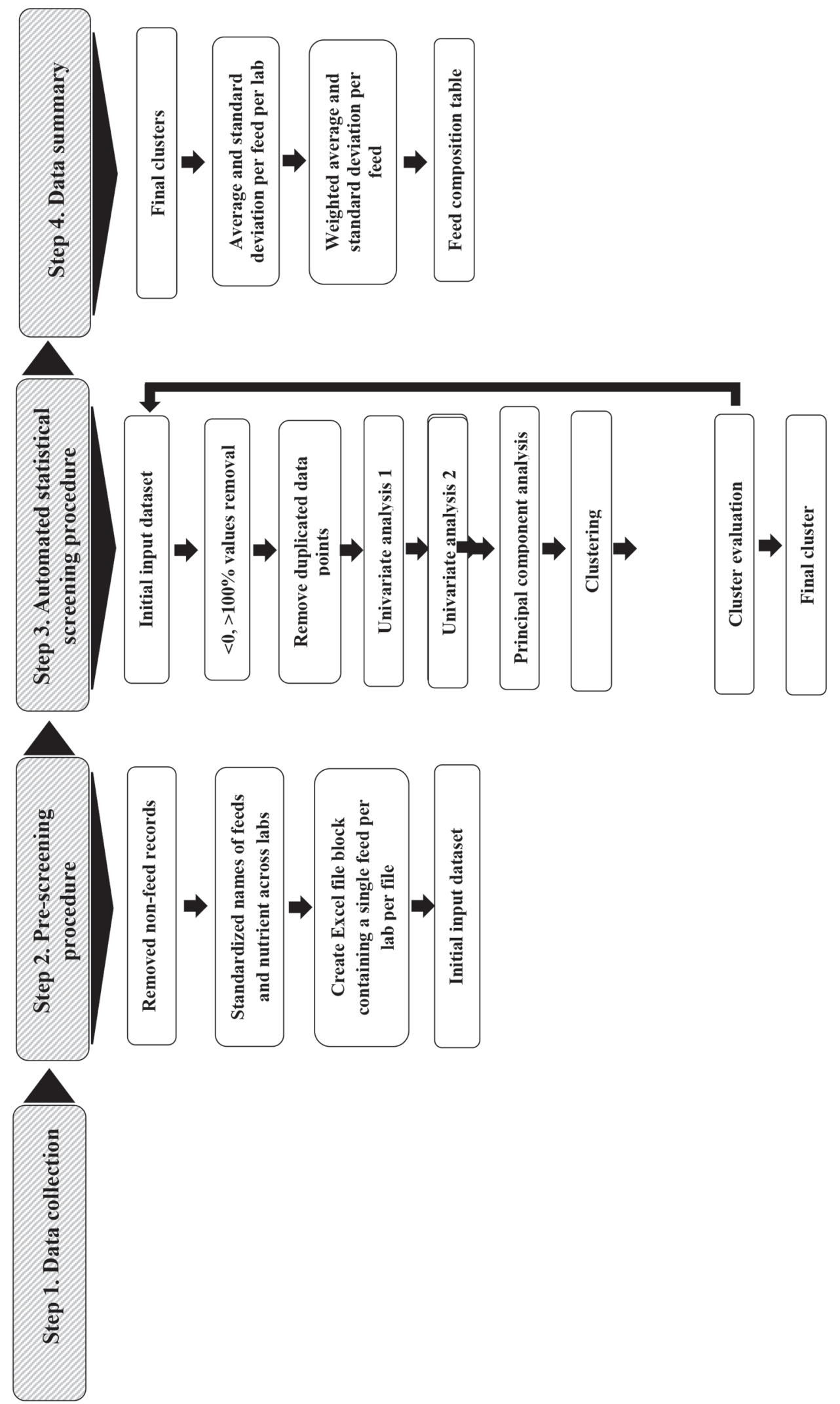

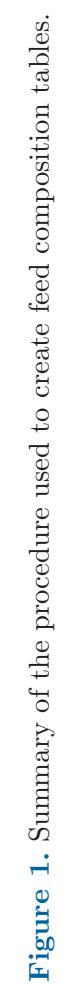


diverse among laboratories. Feeds with similar names across laboratories were assigned with a common feed name. Feed names did not follow the International Feed Name and Number system (Harris et al., 1980); however, attempts were made to use feed names that were consistent with national feed control official standards (AAFCO, 2017). Forages (defined as the aerial parts of certain vegetal species used as feed for ruminants) were rarely identified as species in the raw data sets provided by labs, and, when identified, the number of records was low. Hence, forage records were grouped into 3 main categories: cool-season grasses (including records identified as brome grass, bluegrass, fescue, matua grass, orchardgrass, reed canary grass, and timothy), legumes (including records identified as alfalfa, mixed alfalfa, clover, legume, alfalfa-clover mix), and grass-legume mixture (including records designated as pasture, mixed forages, mixed pastures, grass forage, grass, mixed grass-legume, mixture alfalfa-grass, mixture clover-grass, and meadow grass).

The procedure to standardize names of nutrients was similar to the procedure described for feed names. Nutrients with similar name across laboratories were assigned a common name. Methodologies used to determine nutrients were obtained from each laboratory webpage and evaluated to determine whether nutrients were comparable. A summary for 30 nutrients to be included in feed composition tables can be found in Table 1. In animal nutrition, many assays characterize feeds by measuring the concentration of an "analyte," which is, by definition, the chemical component of interest (Harvey, 2000). This analyte may not be the same as a "nutrient," which is defined as the chemical substance that nourishes (Pond et al., 1995). As an example, NDF is considered an analyte but is not a direct measure of carbohydrate, which is a nutrient. Despite inexact use of the terms, to be consistent with the literature, in this publication the term "nutrient" is used to refer to a chemical component of interest (i.e., analyte).

Finally, data from a single feed were allocated into a different Excel file (version 16.16.18, Microsoft Corp., Redmond, WA), classified according to the laboratory providing data. Each file was the initial input data set to be screened by the automated statistical procedure (Figure 1). The initial library contained 42, 94, 162, and 270 initial input data sets (i.e., feeds) from laboratories 1 through 4, containing 2.76 million feed records in total. The pre-screening step was conducted manually using Excel.

\section{Automated Statistical Screening Procedure}

The objective of the automated statistical screening procedure was to remove outlier data points and detect clusters (defined as identified subgroups of feeds within a large data set; Figure 1). Outliers are defined as observation that differs from most other observations in a data set, generating suspicions on how it was obtained (Hawkins, 1980). Outliers are not necessarily erroneous data points and could represent extreme values within a population (e.g., a mature grass harvested late in a dry season). The statistical screening procedure was conducted automatically, using a primary Python code to automate the process (Python Language, v. 2.7, Python Software Foundation, Wilmington, DE), which executed a secondary SAS code running the statistical screening procedure (SAS v. 9.3, SAS Institute Inc., Cary, NC). Python and SAS codes used to perform the automated statistical screening procedure can be found on the Github webpage (https://github.com/unlhcc/ FeedComposition; see files Screening procedure_b_Python, Screening procedure_Common_Python, and Screening procedure_b_SAS).

The automated statistical screening procedure began with the selection of all initial input data sets. For each initial input data set, the automated screening procedure removed erroneous data points (i.e., nutrient analyses with values $<0$ or $>100)$ and duplicated records (identified as records with identical values for all nutrients contained in the observations).

In the next step, initial input data sets were screened using the 3-step statistical screening procedure previously described by Yoder et al. (2014). The first step in the 3-step statistical screening procedure was a univariate analysis (Figure 1), which removed values more than $\pm 3.5 \mathrm{SD}$ units from the mean for all nutrients. In addition, histograms and correlation matrices for DM, CP, ash, starch, crude fat, NDF, and ADF were generated. The output generated after the univariate analysis was labeled as the filtered data set (Figure 1). Step 2 was a multivariate principal component analysis (PCA; Figure 1; Lever et al., 2017). Before PCA, nutrient values were standardized to a mean of 0 and SD of 1 . Standardized values were used in a PCA using the PRINCOMP procedure of SAS (Yoder et al., 2014). Before the PCA was performed, key nutrients were selected. Key nutrients were an important part of the statistical screening procedure, as they were the variables used to identify feed clusters within an identified feedstuff in an initial data set. In addition, selection of appropriate key nutrients was important to avoid an over-elimination of data through use of a reduced number of nutrients. A PCA requires that all records in a data set contain values for all nutrients. However, because most records did not contain values for the 30 nutrients included in the data sets (Table 1), use of fewer key nutrients reduced the number of records eliminated by the PCA. For 
all initial input data sets (i.e., feeds), assigned key nutrients included those commonly reported for all feeds, such as DM, CP, NDF, and ash. Several other nutrients were designated as key nutrients for specific classes of feeds. For instance, lignin, hemicellulose (determined as NDF - ADF), and Ca were used as key nutrient for some forages; starch was used for grains; fat was used for animal-derived or plant protein feeds; and ethanol-soluble carbohydrate for by-products containing elevated sugar concentrations. Summaries of selected key nutrients for different feeds, classified per laboratory, are shown in Table 2. Data points with PCA scores outside the range of 3.5 SD were removed from the data set as outliers.

Table 1. Nutrients available in the feed composition tables created with the described screening procedure

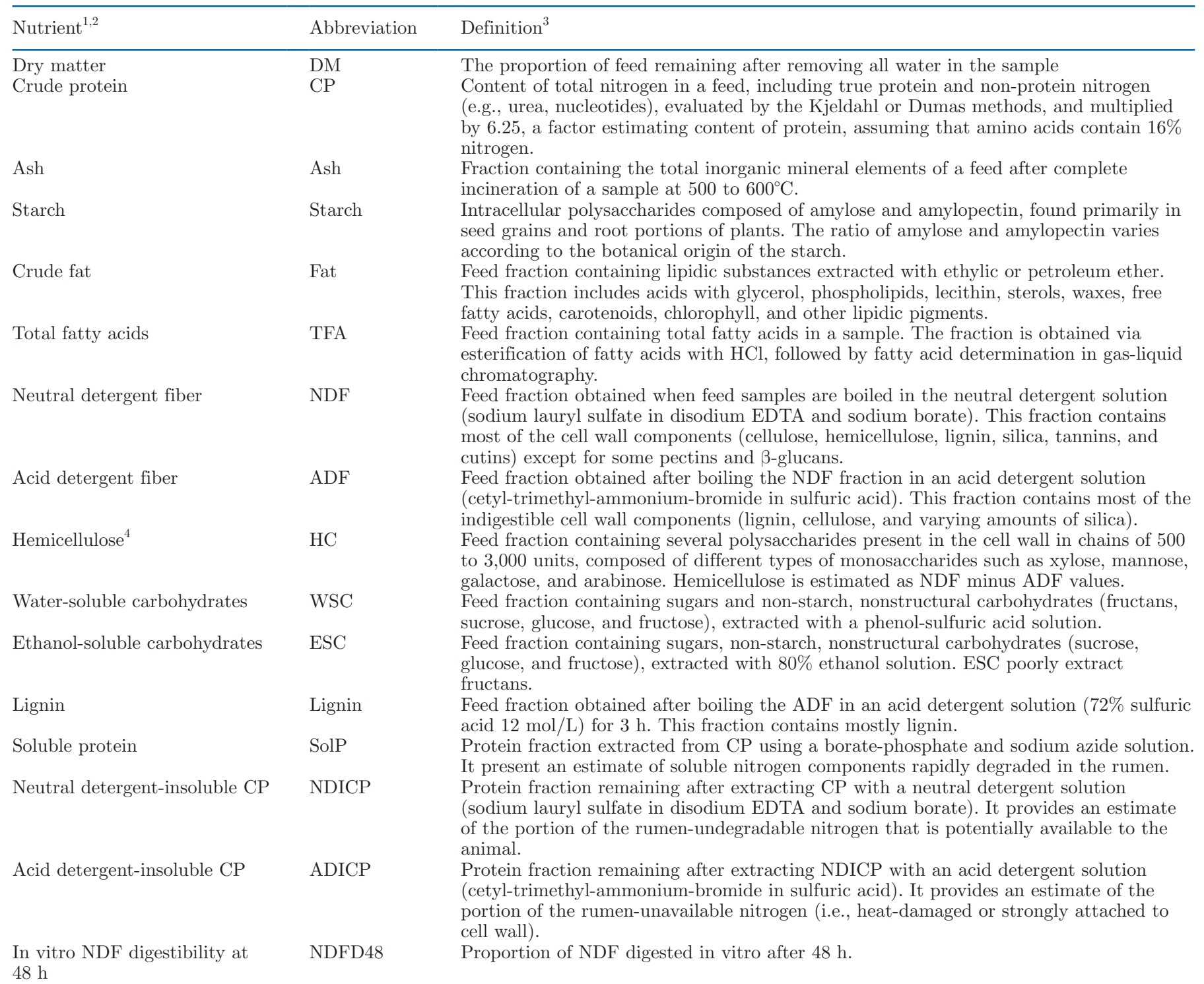

\footnotetext{
${ }^{1}$ By definition, a nutrient is "the chemical substance that nourishes." In the current table, many chemical components cannot be defined as "nutrients"; however, to be consistent with terms used in literature, here a "nutrient" is defined as a "chemical component of interest." Although many feed testing laboratories use NIRS (near infrared spectroscopy) as the main method for nutrient analysis, in this table we define the reference method used to estimate each nutrient.

${ }^{2}$ Feed composition tables created with the described screening procedure will also include values for several minerals that are not defined in the current table, namely, Ca, P, Mg, K, Na, Cl, S, Co, Cu, Fe, Mn, Se, Zn, Mo, and I.

${ }^{3}$ References used for definitions include Van Soest (1963), Sukhija and Palmquist (1988), Licitra et al. (1996), AOAC International (2006), and Hall (2014).

${ }^{4}$ Hemicellulose is a nutrient defined in this table and used as a key nutrient during the statistical screening procedure. However, feed composition tables created with the screening procedure will not report values for hemicellulose.
} 
Tran et al.: DAIRY INDUSTRY TODAY

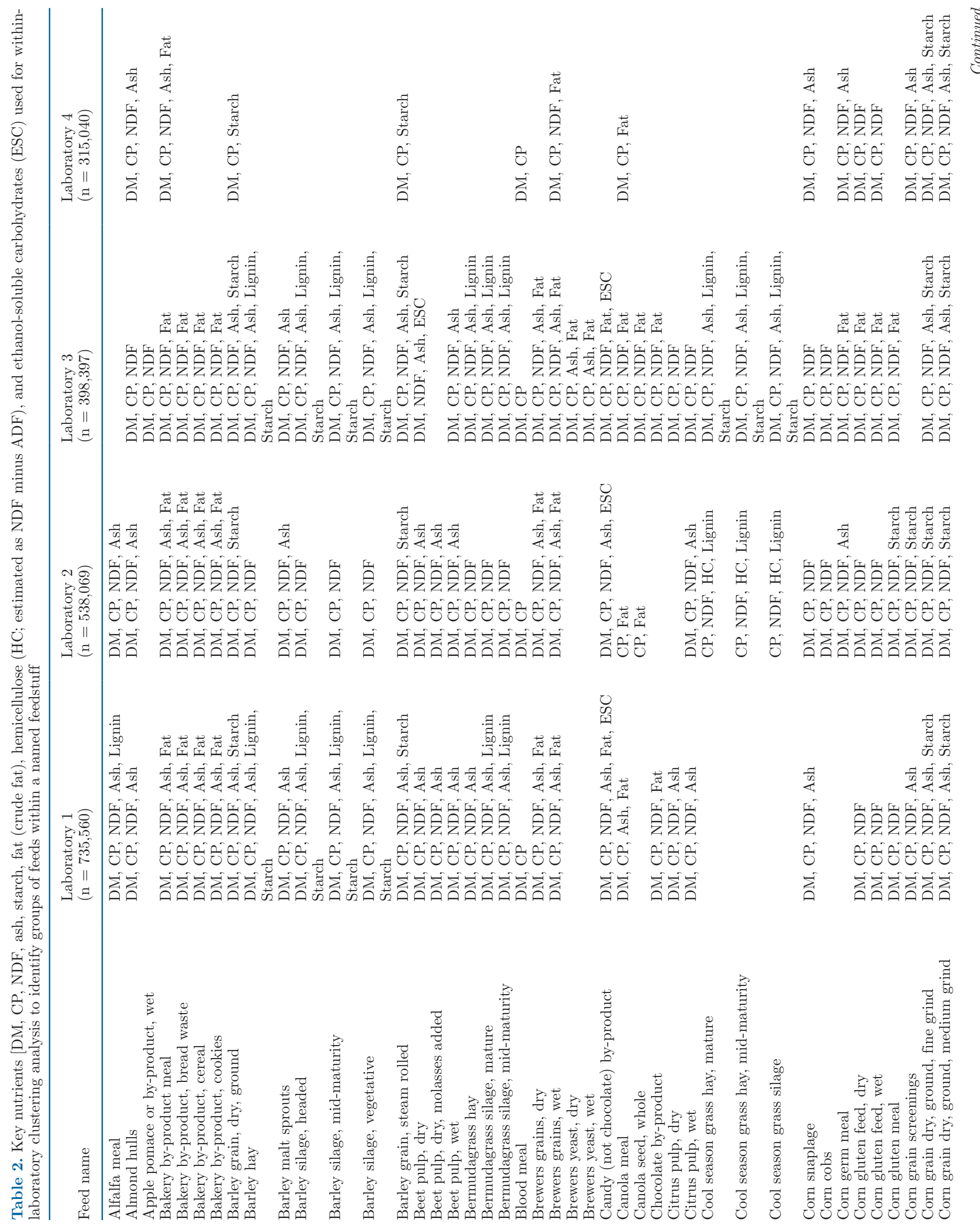




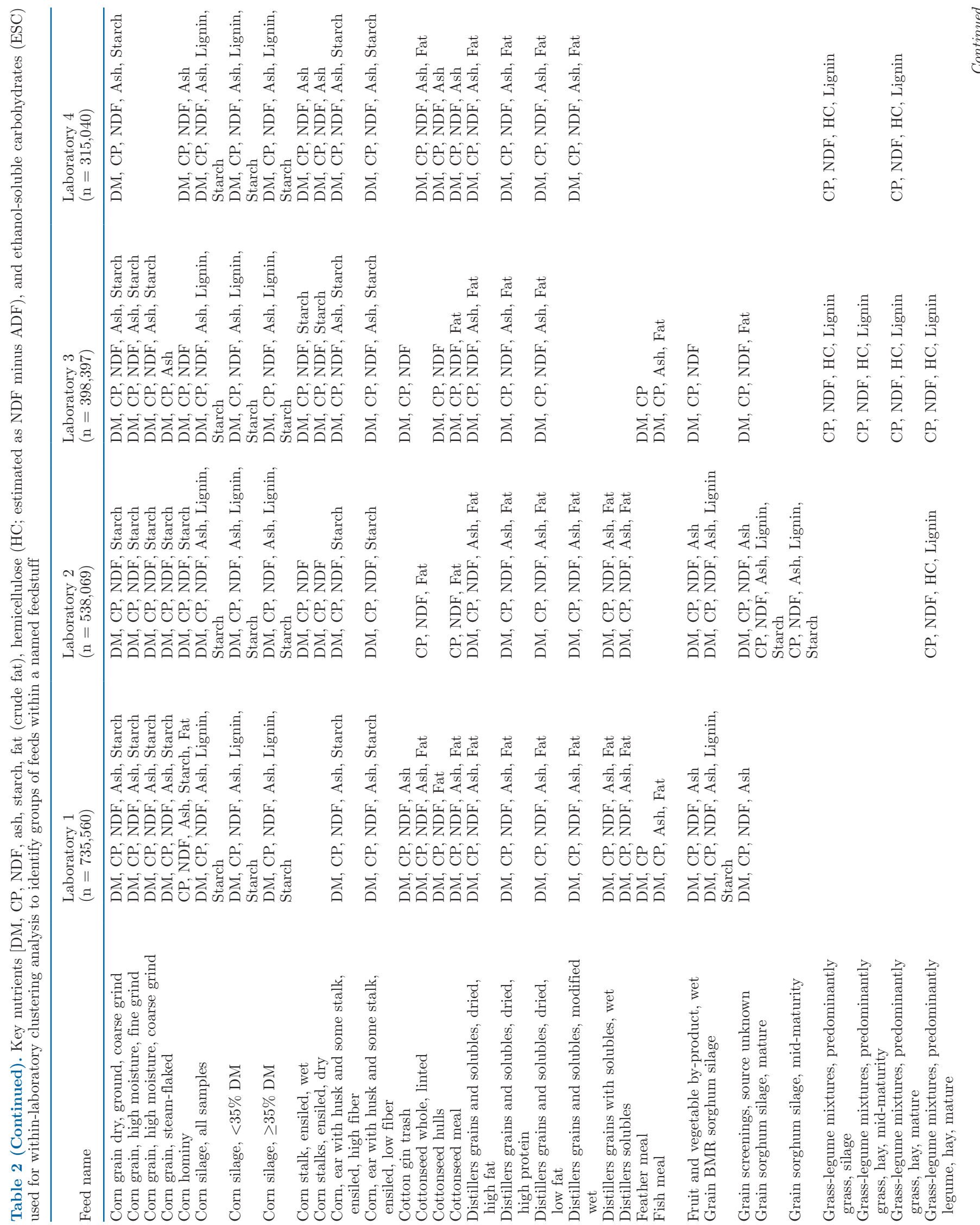


Tran et al.: DAIRY INDUSTRY TODAY

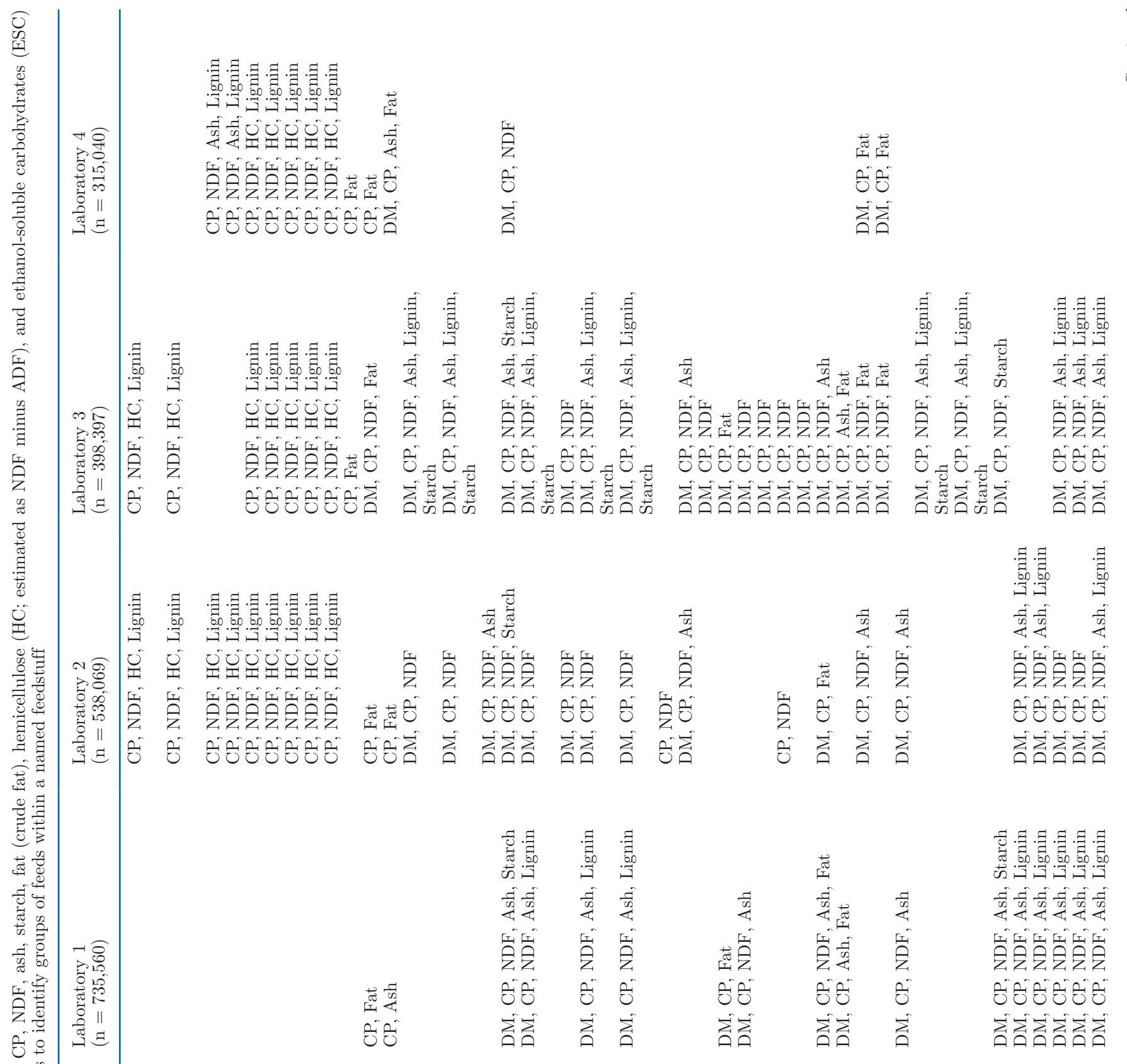


Tran et al.: DAIRY INDUSTRY TODAY

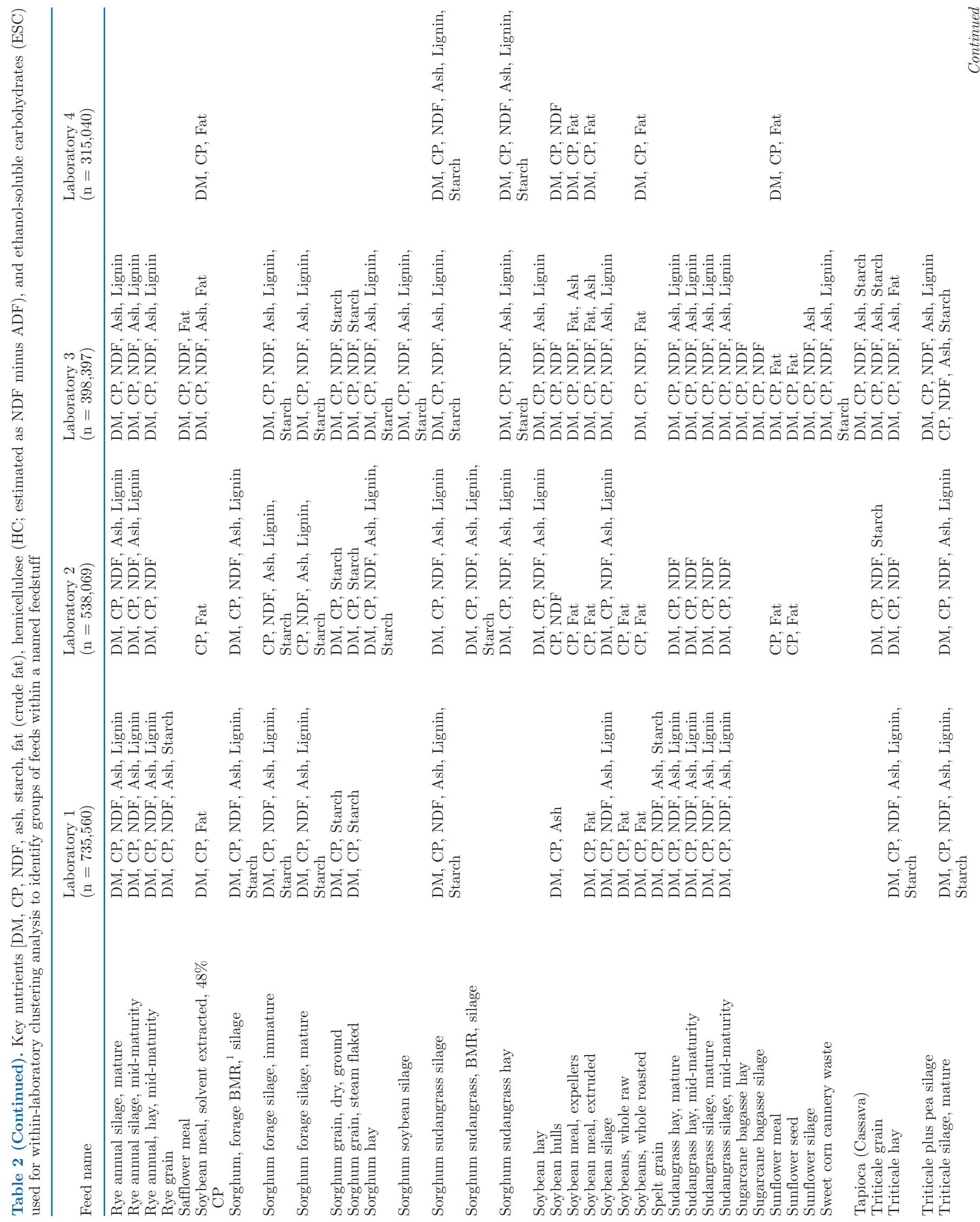


Step 3 involved a multivariate clustering (Figure 1). A 2-stage density linkage cluster analysis was conducted to identify unique groups within a designated initial input data set. Clustering was conducted using the CLUSTER procedure of SAS. Clustering analysis was set up to arbitrarily remove clusters containing less than $10 \%$ of records within an initial data set. When a cluster was removed, the process was repeated automatically and was considered finished when no other cluster was removed. Finally, a second univariate analysis was performed to remove data points exceeding \pm 3.5 SD from the mean within a generated cluster (Yoder et al., 2014). After they were generated, each cluster was evaluated to identify these clusters as specific feeds if possible (Figure 1). Clusters were named using as primary condition the initial feed name assigned during the pre-screening step. Thus, a feed initially identified as soybean in pre-screening remained as soybean during the whole screening procedure. Further identification for feed processing or maturity stage, as in cases of forages, was conducted, evaluating composition of different nutrients such as DM, CP, NDF, crude fat, and starch, among others. Final clusters that were successfully identified were moved into the final step of the procedure, data summary (Figure 1). Otherwise, the final clusters were rejected, and the screening procedure was repeated using different screening parameters (e.g., key nutrients), as described later (Figure 1).

\section{Data Summary}

The automated statistical screening procedure was programmed to deliver summary tables with information for 30 nutrients (Table 1) for each final cluster. Information contained in summary tables for each nutrient included number of records, mean, SD, minimum and maximum values, and 10th and 90th percentiles (Figure 1). Merging data from different labs to obtain population statistics can be problematic because between-laboratory analytical variation is included in the SD estimate. Users probably tend to use a single laboratory, and therefore between-laboratory variation could inflate the SD relative to the true variation within a feed. Therefore we calculated means and SD within laboratory and then calculated a weighted average using the following formulas:

$$
\begin{aligned}
& \text { Weighted mean }=\left[\left(\mu_{1} \times \mathrm{N}_{1}\right)+\left(\mu_{2} \times \mathrm{N}_{2}\right)\right. \\
& \left.\qquad+\left(\mu_{3} \times \mathrm{N}_{3}\right)+\left(\mu_{4} \times \mathrm{N}_{4}\right)\right] / \mathrm{N} \\
& \text { Weighted } \mathrm{SD}=\left[\left(\mathrm{SD}_{1} \times \mathrm{N}_{1}\right)+\left(\mathrm{SD}_{2} \times \mathrm{N}_{2}\right)\right. \\
& \left.+\left(\mathrm{SD}_{3} \times \mathrm{N}_{3}\right)+\left(\mathrm{SD}_{4} \times \mathrm{N}_{4}\right)\right] / \mathrm{N},
\end{aligned}
$$


Table 3. Summary of the automated statistical screening procedure for alfalfa meal with data provided by laboratory 3: initial input data set includes raw data after standardization of feed names and nutrients across laboratories; the filtered data set is the result of eliminating data $\pm 3.5 \mathrm{SD}$ from the average from the initial input data set; and the final cluster is the data set generated after filtered data set is screened with principal component analysis (PCA), clustering, and a second elimination of data \pm 3.5 SD from the average

\begin{tabular}{|c|c|c|c|c|c|c|}
\hline \multirow[b]{3}{*}{ Nutrient $^{1}$} & \multicolumn{6}{|c|}{ Alfalfa meal } \\
\hline & \multicolumn{2}{|c|}{ Initial input data set } & \multicolumn{2}{|c|}{ Filtered data set } & \multicolumn{2}{|c|}{ Final cluster ${ }^{2}$} \\
\hline & $\mathrm{N}$ & $\mu \pm \mathrm{SD}^{3}$ & $\mathrm{~N}$ & $\mu \pm \mathrm{SD}$ & $\mathrm{N}$ & $\mu \pm \mathrm{SD}$ \\
\hline$\overline{\mathrm{DM}}$ & 1,704 & $91.16 \pm 1.42$ & 1,670 & $91.18 \pm 1.35$ & 604 & $91.00 \pm 1.34$ \\
\hline $\mathrm{CP}$ & 1,625 & $18.26 \pm 2.71$ & 1,596 & $18.17 \pm 2.64$ & 602 & $19.76 \pm 1.97$ \\
\hline NDF & 1,536 & $45.97 \pm 6.13$ & 1,509 & $45.95 \pm 6.02$ & 604 & $42.57 \pm 4.32$ \\
\hline Ash & 959 & $11.61 \pm 2.46$ & 934 & $11.48 \pm 2.09$ & 604 & $11.94 \pm 2.15$ \\
\hline Lignin & 837 & $7.62 \pm 1.36$ & 814 & $7.66 \pm 1.31$ & 603 & $7.47 \pm 1.11$ \\
\hline
\end{tabular}

${ }^{1}$ Nutrients used as key nutrients for PCA. Except for DM, all values expressed in DM basis.

${ }^{2}$ Five clusters were deleted for having $<10 \%$ of total recurs. Final cluster was used to construct final feed composition tables.

${ }^{3}$ Average value expressed as percentage $(\mu) \pm \mathrm{SD}$.

where $\mu, \mathrm{SD}$, and $\mathrm{N}_{1}$ through $\mathrm{N}_{4}$ are the mean, $\mathrm{SD}$, and number of records for a nutrient in a feed with data provided by laboratories $1,2,3$, and 4 , respectively. In addition, minimum and maximum values for a nutrient corresponded to the lowest and highest value for a nutrient across summary tables for laboratories 1, 2, 3, and 4 . Finally, 10th and 90th percentile values included in feed composition tables were calculated as the mean of 10th and 90th percentile values available in summary tables for laboratories $1,2,3$, and 4 .

\section{RESULTS AND DISCUSSION}

In total the automated procedure generated 57, 109, 127, and 140 final clusters from laboratories 1 through 4 (Table 2). These clusters were summarized in nutritional information for 174 different feeds and 30 nutrients in 1.48 million records (Tables 1 and 2).
One important feature of the statistical screening procedure was an increase in accuracy for the estimation of variation (i.e., SD) in nutrient composition for tabulated feedstuffs. The increase in the accuracy of the SD estimate was achieved by eliminating outlier data points and by identifying hidden feed clusters within a large data set. Variation in nutrient composition leads to uncertainty in nutrient supply from feeds, compromising the accuracy of formulated rations, and accurate estimates of variation are needed to develop accurate safety factors and to improve diets generated by stochastic formulation.

Clusters generated by the procedure were identified as different feeds using specific nutrients as indicators and expert opinions. For instance, clusters generated from feeds initially identified as forages were classified as follows: storage method, using DM values (i.e., fresh $\approx 15 \% \mathrm{DM}$, silage $\approx 35 \% \mathrm{DM}$, and hay $\approx 80 \% \mathrm{DM}$;

Table 4. Summary of the statistical screening procedure for nutrient composition in distillers grains with solubles (DDGS), with data provided by laboratory 3: initial input data set includes raw data after standardization of feed names and nutrients across laboratories; the filtered data set is the result of eliminating data $\pm 3.5 \mathrm{SD}$ from the average from the initial input data set; and the final cluster is the data set generated after filtered data set is screened with principal component analysis (PCA), clustering, and a second elimination of data $\pm 3.5 \mathrm{SD}$ from the average

\begin{tabular}{|c|c|c|c|c|c|c|c|c|}
\hline \multirow{2}{*}{ Nutrient $^{1}$} & \multicolumn{4}{|c|}{ DDGS } & \multirow{2}{*}{\multicolumn{2}{|c|}{$\begin{array}{l}\text { DDGS, high fat }{ }^{2} \\
\text { Final cluster } 1^{3}\end{array}$}} & \multirow{2}{*}{\multicolumn{2}{|c|}{$\frac{\text { DDGS, low fat }}{2}$}} \\
\hline & \multicolumn{2}{|c|}{ Initial input data set } & \multicolumn{2}{|c|}{ Filtered data set } & & & & \\
\hline$\overline{\mathrm{DM}}$ & 8,351 & $88.44 \pm 5.70$ & 3,657 & $88.51 \pm 2.09$ & 2,517 & $88.28 \pm 1.82$ & 476 & $88.04 \pm 1.14$ \\
\hline $\mathrm{CP}$ & 7,374 & $31.61 \pm 4.69$ & 3,657 & $31.22 \pm 3.93$ & 2,514 & $30.55 \pm 1.92$ & 479 & $32.33 \pm 1.59$ \\
\hline $\mathrm{NDF}$ & 6,511 & $34.19 \pm 4.74$ & 3,657 & $33.78 \pm 3.37$ & 2,517 & $34.40 \pm 2.83$ & 475 & $32.60 \pm 2.48$ \\
\hline
\end{tabular}

${ }^{1}$ Nutrients used as key nutrients for PCA. Except for DM, all values expressed in DM basis.

${ }^{2}$ Name assigned after cluster evaluation. Records with CP $>35 \%$ were removed manually and assigned to feed "DDGS, high protein."

${ }^{3}$ Final clusters were used to construct final feed composition tables.

${ }^{4}$ Average value expressed as percentage $(\mu) \pm$ SD. 
NRC, 2001); maturity stage (immature, mid-mature, and mature) according NDF, ADF, and lignin content; and different grass-legume mixtures, identified as predominantly grass or predominantly legume according to the hemicellulose content (Goering and Van Soest, 1970). The procedure separated clusters that were identified as oilseeds $(\sim 20 \%$ fat $)$, solvent oilseed meals $(\sim 2 \%$ fat), or expeller oilseed meal ( $\sim 6 \%$ fat) from initial data sets that may have been identified as whole cottonseed or whole soybeans. Some by-products were separated into wet or dry based on cluster analysis. Finally, the procedure was helpful in identifying misclassified records in data sets with similar names, such as corn gluten feed versus corn gluten meal, or soybean meal expellers versus soybean meal extruded.

Despite the usefulness of the described procedure, the identification of generated clusters was not always easy. In some cases, a single initial input file generated clusters that were easily identified and moved into the final step of the procedure, data summary (Figure 1). In most cases, however, generated clusters could not be identified. When an initial data set generated clusters that could not be properly identified, the initial input data set was screened following a slightly different procedure. In general, no established protocol existed to repeat the screening procedure, and the new procedure to screen initial input data sets was decided based on the authors' criteria. Some of the new procedures used to generate identifiable clusters included repeating the automated statistical screening procedure using different key nutrients (the automated statistical screening procedure was repeated between 1 and 5 times), merging initial input files initially identified as different feeds to create a new input file, merging clusters generated from different initial input files, retrieving and using clusters removed by the procedure, or manual manipulation of clusters' data sets. The following are examples showing different levels of complexity in how final clusters were generated.

\section{Alfalfa Meal}

Table 3 lists a summary for the statistical screening procedure for a data set initially identified as alfalfa meal. The final cluster for alfalfa meal had a similar average composition for most nutrients when compared with the initial input library; however, SD were reduced in the final cluster. For example, in the case of NDF, the SD of the initial input data set was $6.13 \%$, whereas in the final cluster it was $4.32 \%$ (Table 3 ). The statistical screening procedure removed $63 \%$ of data available from the initial input file and generated a single cluster, and 5 other clusters were removed due to small size $(<10 \%$ of total data).

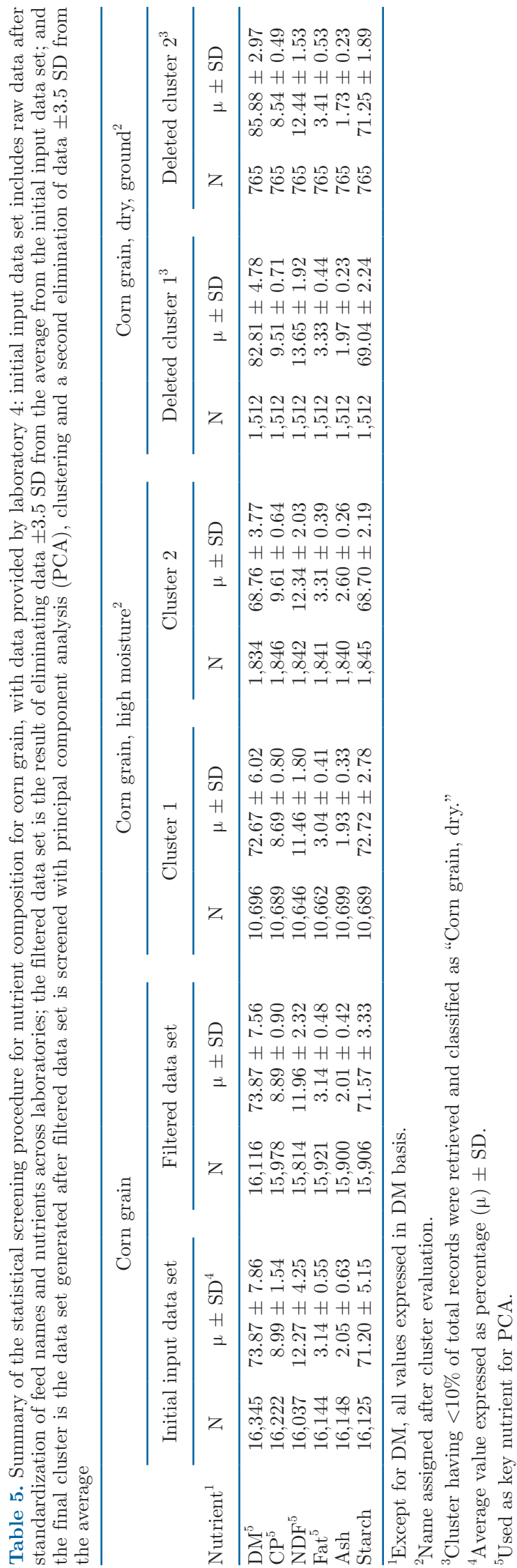


Table 6. Final clusters for 2 types of corn grain: final cluster 1 for corn grain, high moisture, was created by merging data from clusters 1 and 2 in Table 5; final cluster 2 for corn grain, dry, was created by merging data from deleted clusters 1 and 2 from Table 5

\begin{tabular}{lccrrr}
\hline & \multicolumn{2}{c}{ Corn grain, high moisture, fine grind } & & \multicolumn{2}{c}{ Corn grain dry, ground, medium grind } \\
\cline { 2 - 3 } \cline { 5 - 6 } & \multicolumn{2}{c}{ Final cluster $1^{2}$} & & \multicolumn{2}{c}{ Final cluster $2^{2,3}$} \\
\cline { 2 - 3 } Nutrient $^{1}$ & $\mathrm{~N}$ & & $\mathrm{~N}$ & $\mu \pm \mathrm{SD}$ \\
\hline $\mathrm{DM}$ & 12,530 & $72.08 \pm 5.48$ & & 1,268 & $86.94 \pm 2.16$ \\
$\mathrm{CP}$ & 12,535 & $8.87 \pm 0.83$ & & 1,268 & $9.20 \pm 0.87$ \\
$\mathrm{NDF}$ & 12,488 & $11.76 \pm 1.86$ & & 1,268 & $13.32 \pm 2.12$ \\
Fat & 12,503 & $3.09 \pm 0.41$ & & 1,268 & $3.42 \pm 0.55$ \\
Ash & 12,539 & $2.03 \pm 0.39$ & & 1,268 & $1.87 \pm 0.29$ \\
Starch & 12,534 & $71.88 \pm 3.02$ & & 1,268 & $69.57 \pm 2.67$ \\
\hline
\end{tabular}

${ }^{1}$ Except for DM, all values expressed in DM basis.

${ }^{2}$ Final clusters were used to construct final feed composition tables.

${ }^{3}$ Records with $\mathrm{DM}<84 \%$ were deleted manually.

${ }^{4}$ Average value expressed as percentage $(\mu) \pm \mathrm{SD}$.

\section{Distillers Grains and Solubles, Dried}

The statistical screening procedure was used to identify feeds with similar manufacturing processes but differences in feed composition, as is the case for distillers grains and solubles (Schingoethe et al., 2009). Distillers grains are a by-product of the ethanol industry, but the production process may be modified to result in feeds that can be further differentiated. Table 4 lists a summary of the statistical screening procedure for an input data set initially identified as distillers grains and solubles, dried. The statistical screening procedure removed $61 \%$ of data initially designated as distillers grains and solubles and generated 2 clusters that were identified as distillers grain with solubles, dried, high fat (final cluster 1 : fat $=13.59 \% \pm 1.80$, Table 4 ), and distillers grain with solubles, dried, low fat (final cluster 2: fat $=9.94 \% \pm 2.33$, Table 4). After cluster evaluation, we also removed records with $\mathrm{CP}>35 \%$ and assigned them to a different cluster, generated from a different initial input data set, identified as distillers grain with solubles, high protein (data not shown), to match market offerings of distillers grain products (Schingoethe et al., 2009). Aside from fat, mean nutrient composition was similar for data in the input library, the filtered library, and both generated clusters. Standard deviation tended to be lower in clusters than in the initial input file, especially for DM (SD for initial input data set = $5.70 \%$, final cluster $1=1.82 \%$, final cluster $2=1.14 \%$ ) and $\mathrm{CP}$ (SD for initial input data set $=4.69 \%$, final cluster $1=1.92 \%$, final cluster $2=1.59 \%$; Table 4 ).

\section{Corn Grain}

As explained previously, the automated statistical screening procedure was programmed to remove clusters containing less than $10 \%$ of records in an initial input data set. In some cases, however, removed clus-

Table 7. Summary of the statistical screening procedure for nutrient composition for corn gluten feed, with data provided by laboratory 1 : initial input data set includes raw data after standardization of feed names and nutrients across laboratories; the filtered data set is the result of eliminating data $\pm 3.5 \mathrm{SD}$ from the average from the initial input data set; the final cluster is the data set generated after filtered data set is screened with principal component analysis (PCA), clustering, and a second elimination of data \pm 3.5 SD from the average

\begin{tabular}{|c|c|c|c|c|c|c|c|c|}
\hline \multirow[b]{2}{*}{ Nutrient $^{1}$} & \multicolumn{4}{|c|}{ Corn gluten feed } & \multicolumn{2}{|c|}{$\begin{array}{c}\text { Corn gluten feed, } \text { dry }^{2} \\
\text { Cluster } 1\end{array}$} & \multicolumn{2}{|c|}{$\begin{array}{c}\text { Corn gluten feed, wet }{ }^{2} \\
\text { Cluster } 2\end{array}$} \\
\hline & $\mathrm{N}$ & $\mu \pm \mathrm{SD}^{3}$ & $\mathrm{~N}$ & $\mu \pm \mathrm{SD}$ & $\mathrm{N}$ & $\mu \pm \mathrm{SD}$ & $\mathrm{N}$ & $\mu \pm \mathrm{SD}$ \\
\hline$\overline{\mathrm{DM}^{4}}$ & 1,573 & $81.18 \pm 17.08$ & 1,487 & $81.13 \pm 17.10$ & 616 & $88.29 \pm 1.97$ & 195 & $44.47 \pm 6.23$ \\
\hline $\mathrm{CP}^{4}$ & 1,407 & $23.80 \pm 5.88$ & 1,370 & $23.23 \pm 2.46$ & 616 & $23.39 \pm 2.22$ & 194 & $23.08 \pm 2.13$ \\
\hline $\mathrm{NDF}^{4}$ & 851 & $35.64 \pm 5.96$ & 837 & $35.87 \pm 4.91$ & 592 & $35.59 \pm 4.19$ & 195 & $37.32 \pm 4.99$ \\
\hline Starch & 292 & $16.32 \pm 6.20$ & 287 & $16.28 \pm 5.80$ & 158 & $15.54 \pm 4.57$ & 105 & $17.18 \pm 6.25$ \\
\hline
\end{tabular}

${ }^{1}$ Except for DM, all values expressed in DM basis.

${ }^{2}$ Name assigned after cluster evaluation.

${ }^{3}$ Average value expressed as percentage $(\mu) \pm$ SD.

${ }^{4}$ Used as key nutrient for PCA. 
ters provided useful information. The statistical screening procedure for an initial input data set designated as corn grain generated 5 clusters, from which 3 were deleted for having $<10 \%$ of total data. Given the DM values for generated clusters $1(\mathrm{DM}=72.67 \% \pm 6.02$, Table 5) and $2(\mathrm{DM}=68.76 \% \pm 3.77$, Table 5$)$, these were identified as corn grain, high moisture. Three deleted clusters were evaluated, and 2 deleted clusters were retrieved and identified as corn grain, dry, according to $\mathrm{DM}$ values (deleted cluster $1 \mathrm{DM}=82.81 \% \pm$ 4.78; deleted cluster $2 \mathrm{DM}=85.88 \% \pm 2.97$; Table 5 ). The final cluster for corn grain, high moisture (Table 6 ), was created by merging clusters 1 and 2 from Table 5 , whereas the final cluster for corn grain, dry (Table 6 ), was created by merging deleted clusters 1 and 2 from Table 5 .

\section{Corn Gluten Feed and Corn Gluten Meal}

The automated statistical screening procedure was a useful tool to identify commonly misclassified feeds, as was the case of corn gluten feed and corn gluten meal. Tables 7, 8, and 9 summarize the statistical screening procedure used to obtain final clusters for corn gluten feed, dry or wet, and corn gluten meal. The automated statistical screening procedure applied to the initial input data set identified as corn gluten feed removed $47 \%$ of data initially available and generated 2 clusters. Considering that the main difference between clusters was DM, generated clusters were identified as corn gluten feed, dry (cluster $1, \mathrm{DM}=88.29 \% \pm 1.97$, Table 7) and corn gluten feed, wet (cluster 2, DM = $44.47 \% \pm 6.23$, Table 7). The automated statistical screening procedure was applied to the second initial input data set identified as corn gluten meal (Table 8 ). The automated procedure removed $65 \%$ of data initially available and generated 3 clusters. Generated clusters differed mainly in DM and $\mathrm{CP}$ values and were identified as corn gluten meal (cluster 1, DM = $90.00 \% \pm 1.49, \mathrm{CP}=68.81 \% \pm 3.49$, Table 8), corn gluten feed, wet (cluster $2, \mathrm{DM}=41.83 \% \pm 4.39, \mathrm{CP}$ $=22.94 \% \pm 2.66$, Table 8 ), and corn gluten feed, dry (cluster $3, \mathrm{DM}=88.91 \% \pm 2.26, \mathrm{CP}=22.08 \% \pm 5.49$, Table 8). The creation of identifiable clusters reduced $\mathrm{SD}$ values for several nutrients. For instance, in the initial data set identified as corn gluten feed (Table 7) the SD for DM decreased from $17.08 \%$ in the initial input data set to $1.97 \%$ in cluster 1 and $6.23 \%$ in cluster 2. Similarly, in the initial data set identified as corn gluten meal (Table 8), the SD for DM and CP decreased from $16.14 \%$ for DM and $20.28 \%$ for CP in the initial input data set to values ranging from $1.46 \%$ to $4.39 \%$ for DM, and from $2.66 \%$ to $5.49 \%$ for CP in clusters 1, 2, and 3. Final clusters were created by

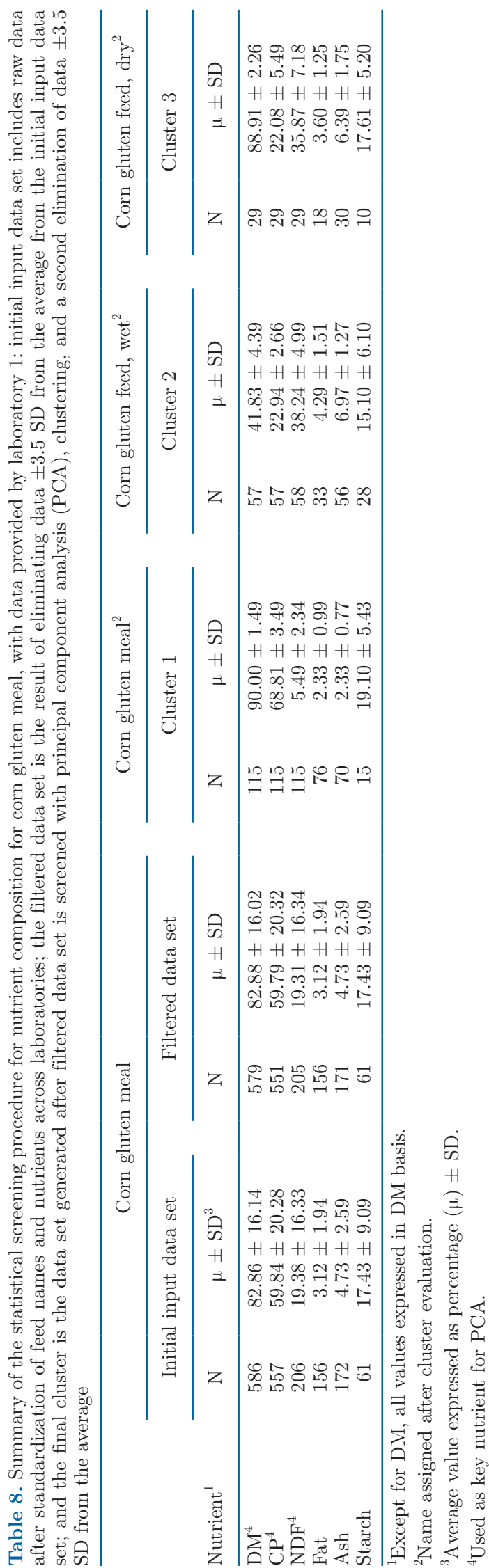


Table 9. Final clusters for corn gluten feed, wet or dry, and corn gluten meal: final cluster 1 for corn gluten feed, dry, was created by merging data from cluster 1 in Table 7 and cluster 3 in Table 8; final cluster 2 for corn gluten feed, wet, was created merging data from cluster 2 in Table 7 and cluster 2 in Table 8; final cluster 3 is equivalent to cluster 1 in Table 8

\begin{tabular}{|c|c|c|c|c|c|c|}
\hline \multirow[b]{3}{*}{ Nutrient $^{1}$} & \multirow{2}{*}{\multicolumn{2}{|c|}{$\begin{array}{c}\text { Corn gluten feed, dry } \\
\text { Final cluster } 1^{2}\end{array}$}} & \multirow{2}{*}{\multicolumn{2}{|c|}{$\frac{\text { Corn gluten feed, wet }}{\text { Final cluster } 2^{2}}$}} & \multirow{2}{*}{\multicolumn{2}{|c|}{$\begin{array}{c}\text { Corn gluten meal } \\
\text { Final cluster } 3^{2}\end{array}$}} \\
\hline & & & & & & \\
\hline & $\mathrm{N}$ & $\mu \pm \mathrm{SD}^{3}$ & $\mathrm{~N}$ & $\mu \pm \mathrm{SD}$ & $\mathrm{N}$ & $\mu \pm \mathrm{SD}$ \\
\hline $\mathrm{DM}$ & 645 & $88.32 \pm 1.99$ & 252 & $43.87 \pm 5.87$ & 115 & $90.00 \pm 1.49$ \\
\hline $\mathrm{CP}$ & 645 & $23.33 \pm 2.47$ & 251 & $23.05 \pm 2.26$ & 115 & $68.81 \pm 3.49$ \\
\hline NDF & 646 & $35.60 \pm 4.36$ & 253 & $37.53 \pm 4.99$ & 115 & $5.49 \pm 2.34$ \\
\hline Fat & 407 & $3.81 \pm 0.96$ & 144 & $4.10 \pm 1.15$ & 76 & $2.33 \pm 0.99$ \\
\hline Ash & 619 & $7.68 \pm 1.63$ & 241 & $7.21 \pm 1.35$ & 70 & $2.33 \pm 0.77$ \\
\hline Starch & 168 & $15.67 \pm 4.62$ & 133 & $16.74 \pm 6.22$ & 15 & $19.10 \pm 5.43$ \\
\hline
\end{tabular}

${ }^{1}$ Except for DM, all values expressed in DM basis.

${ }^{2}$ Final clusters were used to construct feed composition tables.

${ }^{3}$ Average value expressed as percentage $(\mu) \pm \mathrm{SD}$

merging clusters identified as the same feed in Tables 7 and 8 , as described in Table 9 .

\section{Legume Hay}

As stated previously, the automated screening procedure was useful to classify forages according to storage method and maturity stage. No attempt to separate the 3 main forages classes (cool season grasses, legumes, and grass-legume mixtures) into single species was made, because harvesting, conservation method, and maturity stages are more important than specific species to determine forage quality (Cherney et al., 1993). When applied to an initial input data set designated as legume forage (Table 10), the automated statistical screening procedure removed $22 \%$ of initial data and generated 2 clusters identified as legume hay (cluster $1, \mathrm{DM}=89.17 \% \pm 4.24$ ) and legume silage (cluster 2 , $\mathrm{DM}=42.90 \% \pm 9.59)$. A second initial input data set designated as legume hay (Table 11) was screened with the automated statistical procedure. After screening, the initial input data set for legume hay generated 2 clusters identified as legume hay, immature (cluster 1, $\mathrm{DM}=87.34 \% \pm 2.32, \mathrm{NDF}=34.25 \% \pm 3.44)$, and legume hay, mature (Cluster $1, \mathrm{DM}=88.00 \% \pm 1.92$, $\mathrm{NDF}=43.03 \% \pm 4.16$ ), eliminating $25 \%$ of data initially available in the process. After cluster evaluation, initial input data sets for legume forage (Table 10) and legume hay (Table 11) were merged, and records having $\mathrm{DM}<70 \%$ were manually removed, creating a new input data set designated as legume hay (Table 12). Unlike screening performed previously in Tables 10 and 11, the statistical procedure for the new input data set for legume hay included hemicellulose (calculated as $\mathrm{NDF}-\mathrm{ADF}$ ) as a key nutrient for PCA. We did so because hemicellulose content can be used to differentiate between legumes and grasses (Goering and Van Soest, 1970). After employing the statistical screening proce-

Table 10. Summary of the statistical screening procedure for nutrient composition for legume forage, with data provided by laboratory 1 : initial input data set includes raw data after standardization of feed names and nutrients across laboratories; the filtered data set is the result of eliminating data $\pm 3.5 \mathrm{SD}$ from the average from the initial input data set; and the final cluster is the data set generated after filtered data set is screened with principal component analysis (PCA), clustering, and a second elimination of data $\pm 3.5 \mathrm{SD}$ from the average

\begin{tabular}{|c|c|c|c|c|c|c|c|c|}
\hline \multirow[b]{2}{*}{ Nutrient $^{1}$} & \multicolumn{4}{|c|}{ Legume forage } & \multicolumn{2}{|c|}{$\begin{array}{c}\text { Legume hay }^{2} \\
\text { Cluster } 1\end{array}$} & \multicolumn{2}{|c|}{$\begin{array}{c}\text { Legume silage }^{2} \\
\text { Cluster } 2\end{array}$} \\
\hline & $\mathrm{N}$ & $\mu \pm \mathrm{SD}^{3}$ & $\mathrm{~N}^{1}$ & $\mu \pm \mathrm{SD}$ & $\mathrm{N}^{1}$ & $\mu \pm \mathrm{SD}$ & $\mathrm{N}^{1}$ & $\mu \pm \mathrm{SD}$ \\
\hline $\mathrm{DM}$ & 191,764 & $61.58 \pm 24.16$ & 152,412 & $58.92 \pm 23.44$ & 51,649 & $89.17 \pm 4.24$ & 97,400 & $42.90 \pm 9.59$ \\
\hline $\mathrm{CP}$ & 189,388 & $20.81 \pm 2.59$ & 152,412 & $20.93 \pm 2.33$ & 52,388 & $20.89 \pm 2.42$ & 97,316 & $21.03 \pm 2.17$ \\
\hline NDF & 181,214 & $40.32 \pm 5.83$ & 152,412 & $40.61 \pm 5.24$ & 52,379 & $39.75 \pm 5.44$ & 97,325 & $40.94 \pm 4.84$ \\
\hline Lignin & 165,208 & $7.17 \pm 1.23$ & 152,412 & $7.13 \pm 1.13$ & 52,312 & $6.94 \pm 1.06$ & 97,301 & $7.23 \pm 1.11$ \\
\hline
\end{tabular}

${ }^{1}$ Nutrients used as key nutrient for PCA. Except for DM, all values expressed in DM basis.

${ }^{2}$ Name assigned after cluster evaluation.

${ }^{3}$ Average value expressed as percentage $(\mu) \pm$ SD. 
Table 11. Summary of the statistical screening procedure for nutrient composition for legume hay, with data provided by laboratory 1: initial input data set includes raw data after standardization of feed names and nutrients across laboratories; the filtered data set is the result of eliminating data $\pm 3.5 \mathrm{SD}$ from the average from the initial input data set; and the final cluster is the data set generated after filtered data set is screened with principal component analysis (PCA), clustering, and a second elimination of data $\pm 3.5 \mathrm{SD}$ from the average

\begin{tabular}{|c|c|c|c|c|c|c|c|c|}
\hline \multirow{2}{*}{ Nutrient $^{1}$} & \multicolumn{4}{|c|}{ Legume hay } & \multirow{2}{*}{\multicolumn{2}{|c|}{$\begin{array}{c}\text { Legume hay, immature }^{2} \\
\text { Cluster } 1\end{array}$}} & \multirow{2}{*}{\multicolumn{2}{|c|}{$\begin{array}{c}\text { Legume hay, mature }^{2} \\
\text { Cluster } 2\end{array}$}} \\
\hline & \multicolumn{2}{|c|}{ Initial input data set } & \multicolumn{2}{|c|}{ Filtered data set } & & & & \\
\hline $\mathrm{DM}$ & 564 & $87.68 \pm 4.31$ & 432 & $87.53 \pm 2.53$ & 252 & $87.34 \pm 2.32$ & 168 & $88.00 \pm 1.92$ \\
\hline $\mathrm{CP}$ & 564 & $20.73 \pm 2.70$ & 432 & $20.98 \pm 2.60$ & 252 & $22.35 \pm 1.82$ & 168 & $19.15 \pm 1.79$ \\
\hline NDF & 531 & $38.37 \pm 6.27$ & 432 & $37.99 \pm 6.11$ & 252 & $34.25 \pm 3.44$ & 169 & $43.03 \pm 4.16$ \\
\hline Lignin & 479 & $6.85 \pm 1.10$ & 432 & $6.82 \pm 1.08$ & 253 & $6.21 \pm 0.64$ & 168 & $7.83 \pm 0.73$ \\
\hline
\end{tabular}

${ }^{1}$ Nutrients used as key nutrient for PCA. Except for DM, all values expressed in DM basis.

${ }^{2}$ Name assigned after cluster evaluation.

${ }^{3}$ Average value expressed as percentage $(\mu) \pm$ SD.

dure, the new input data set for legume hay (Table 12) generated 2 clusters, identified as legume hay, immature (cluster $1, \mathrm{DM}=89.69 \% \pm 3.85, \mathrm{NDF}=38.41 \% \pm$ 4.24 ), and legume hay, mature (cluster $1, \mathrm{DM}=86.42 \%$ $\pm 4.76, \mathrm{NDF}=48.68 \% \pm 3.39$ ), eliminating $32 \%$ of data initially available in the process. No generated cluster was classified as grass-legume mixture, due to the relatively low content of hemicellulose in both clusters (hemicellulose, cluster $1=6.89 \% \pm 1.80$, cluster 2 $=10.08 \% \pm 1.65$ ), whereas grass-legume mixtures hays in this database had an average hemicellulose concentration ranging between 16 and $21 \%$ (data not shown). Two other examples of the cluster evaluation procedure can be found in Supplemental File S1 (https://doi.org/ 10.3168/jds.2019-16702).
The automated statistical screening procedure deleted $46 \%$ of initially available data. Using the same statistical screening procedure, Yoder et al. (2014) reported an average removal rate of $13.5 \%$ from the initial available data. The higher removal rate in the current procedure than in the findings of Yoder et al. (2014) may be due to the complex cluster evaluation procedure employed in the current study. Yoder et al. (2014) only analyzed 15 feeds with data provided by 2 labs. In addition, Yoder et al. (2014) ended with cluster identification after running the screening procedure a single time, whereas in the current work the automated statistical screening procedure was repeated between 1 and 5 times, with frequent manual removal of data. A greater removal rate was prevented by repeating the

Table 12. Summary of the statistical screening procedure for nutrient composition for legume hay, with data provided by laboratory 1: initial input data set includes raw data after standardization of feed names and nutrients across laboratories; the filtered data set is the result of eliminating data $\pm 3.5 \mathrm{SD}$ from the average from the initial input data set; and the final cluster is the data set generated after filtered data set is screened with principal component analysis (PCA), clustering, and a second elimination of data \pm 3.5 SD from the average

\begin{tabular}{|c|c|c|c|c|c|c|c|c|}
\hline Nutrient $^{1}$ & \multicolumn{4}{|c|}{ Legume hay } & \multicolumn{2}{|c|}{$\begin{array}{c}\text { Legume hay, immature }^{2} \\
\text { Final cluster } 1^{3}\end{array}$} & \multicolumn{2}{|c|}{$\begin{array}{c}\text { Legume hay, mature } \\
\text { Final cluster } 2^{3}\end{array}$} \\
\hline DM & 77,616 & $89.19 \pm 4.42$ & 75,557 & $89.21 \pm 4.35$ & 45,675 & $89.69 \pm 3.85$ & 6,632 & $86.42 \pm 4.76$ \\
\hline $\mathrm{CP}^{5}$ & 76,479 & $20.66 \pm 2.81$ & 74,710 & $20.82 \pm 2.47$ & 46,324 & $21.29 \pm 2.11$ & 6,631 & $18.00 \pm 2.00$ \\
\hline $\mathrm{NDF}^{5}$ & 74,620 & $39.33 \pm 6.36$ & 72,960 & $39.06 \pm 5.68$ & 46,397 & $38.41 \pm 4.24$ & 6,632 & $48.68 \pm 3.39$ \\
\hline Ash & 66,785 & $10.70 \pm 2.00$ & 65,336 & $10.74 \pm 1.86$ & 46,221 & $10.89 \pm 1.51$ & 6,596 & $9.09 \pm 1.59$ \\
\hline
\end{tabular}

${ }^{1}$ Except for DM, all values expressed in DM basis.

${ }^{2}$ Name assigned after cluster evaluation.

${ }^{3}$ Final clusters were used to construct feed composition tables.

${ }^{4}$ Average value expressed as percentage $(\mu) \pm$ SD.

${ }^{5}$ Nutrients used as key nutrient for PCA.

${ }^{6}$ Calculated as NDF - ADF. 
screening procedure with different key nutrients each time. As stated previously, a PCA requires that all variables used as key nutrients contain all the records (Lever et al., 2017). Thus, more records were retained when the screening procedure was repeated excluding nutrients with the smallest numbers of records.

Univariate procedures are commonly used to eliminate outliers in feed composition data sets (Maroto-Molina et al., 2013). However, the ability of such methods to identify outliers may be imprecise and inaccurate, because they assume that variables (i.e., nutrients) in a feed are independent (Yu, 2005; Yoder et al., 2014). Because many nutrients within a feed are correlated, multivariate methods are better at identifying outliers and can be used to generate accurate and robust estimates of both the mean and associated covariances. For example, using a univariate procedure, a sample identified as legume silage containing 50\% NDF and 25\% $\mathrm{CP}$ would not be considered an outlier if the estimate for $\mathrm{NDF}$ and $\mathrm{CP}$ are within $\pm 3.5 \mathrm{SD}$ from the mean of the population. However, because CP and NDF are negatively correlated, the likelihood that this sample truly contains $50 \% \mathrm{NDF}$ and $25 \% \mathrm{CP}$ is extremely small. Such a sample would be identified as an outlier using multivariate but not univariate procedures. An additional challenge when employing a univariate procedure is that some nutrients within feedstuffs do not fit a normal distribution, and those data should be evaluated using methods for non-Gaussian distributions (Yoder et al., 2014).

The described automated procedure greatly reduced the time needed to screen data sets and allowed simultaneous analysis of all feeds within or across laboratories. In addition, the described procedure helped in the development of one of the largest feed composition data sets and tables currently available. However, preprocessing, cluster evaluation, and data summary steps were performed manually. Hence, overall it was still a time-consuming process. Automation of the whole datamanagement process, including pre-processing, statistical screening, cluster evaluation, and data summary is also required for a full-scale implementation needed to develop real-time databases and online feed composition tables. In this regard, the developed feed composition data set described in the current manuscript could be the first step toward developing machine-learning algorithms, aiming to automate the classification of feeds records in large data sets.

\section{ACKNOWLEDGMENTS}

This research was a component of the National Animal Nutrition Program (NRSP-9), which supports the use and sharing of feed composition and animal performance data, resources for nutritional modeling, model code, and knowledge on feed analysis methods. The authors thank the NANP-NRSP-9 program, specifically A. N. Hristov (The Pennsylvania State University, University Park, PA) and M. Nelson (Washington State University, Pullman, WA), who reviewed final data. The project was also supported by state and federal funds appropriated to the University of Nebraska-Lincoln and The Ohio State University, and by funding from the USDA-Agricultural Research Service (Washington, DC). We also thank the feed analysis laboratories that contributed data and made this study possible: Dairyland Laboratories, Arcadia, WI; Cumberland Valley Analytical Services, Waynesboro, PA; Rock River Laboratory Inc., Watertown, WI; and Dairy One, Ithaca, NY.

\section{REFERENCES}

AAFCO. 2017. Official Publication: Association of American Feed Control Officials. Association of American Feed Control Officials Inc., Champaign, IL.

AOAC. 2006. Official Methods of Analysis. 18th ed. Association of Official Analytical Chemists, Arlington, VA.

Cherney, D. J. R., J. H. Cherney, and R. F. Lucey. 1993. In vitro digestion kinetics and quality of perennial grasses as influenced by forage maturity. J. Dairy Sci. 76:790-797. https://doi.org/10 .3168/jds.S0022-0302(93)77402-0.

Federatie Nederlandse Diervoederketen. 2016. CVB Feed Table 2016: Chemical Composition and Nutritional Values of Feedstuffs. Federatie Nederlandse Diervoederketen, Wageningen, the Netherlands.

Goering, H. K., and P. J. Van Soest. 1970. Forage Fiber Analysis: Apparatus, Reagents, Procedures, and Some Applications. Agriculture Handbook No. 379. United States Department of Agriculture, Washington, DC.

Hall, M. B. 2014. Selection of an empirical detection method for determination of water-soluble carbohydrates in feedstuffs for application in ruminant nutrition. Anim. Feed Sci. Technol. 198:28-37. https://doi.org/10.1016/j.anifeedsci.2014.08.009.

Harris, L. E., H. Haendler, R. Riviere, and L. U. Rechoussat. 1980. International Feed Databank System: An Introduction Into the System with Instructions for Describing Feed and Recording Data. International Network of Feed Information Centers (INFIC), Logan, UT.

Harvey, D. 2000. Modern Analytical Chemistry. McGraw-Hill, Boston, MA.

Hawkins, D. 1980. Identification of Outliers. Chapman and Hall, London, UK.

Lever, J., M. Krzywinski, and N. Altman. 2017. Principal component analysis. Nat. Methods 14:641-642. https://doi.org/10.1038/ nmeth. 4346 .

Licitra, G., T. M. Hernandez, and P. J. Van Soest. 1996. Standardization of procedures for nitrogen fractionation of ruminant feeds. Anim. Feed Sci. Technol. 57:347-358.

Lokhorst, C., R. M. de Mol, and C. Kamphuis. 2019. Invited review: Big data in precision dairy farming. Animal 13:1519-1528. https:/ /doi.org/10.1017/S1751731118003439.

Ministry of Agriculture, Fisheries and Food. 1992. Feed Composition: UK Tables of Feed Composition and Nutritive Value for Ruminants. Chalcombe Publications, Canterbury, UK.

Maroto-Molina, F., A. Gómez-Cabrera, J. E. Guerrero-Ginel, A. Garrido-Varo, D. Sauvant, G. Tran, V. Heuzé, and D. C. Pérez-Marín. 
2013. Data pre-processing to improve the mining of large feed databases. Animal 7:1128-1136.

Morota, G., R. V. Ventura, F. F. Silva, M. Koyama, and S. C. Fernando. 2018. Big data analytics and precision animal agriculture symposium: Machine learning and data mining advance predictive big data analysis in precision animal agriculture1. J. Anim. Sci. 96:1540-1550. https://doi.org/10.1093/jas/sky014.

NASEM. 2016. Nutrient Requirements of Beef Cattle. 8th rev. ed. Natl. Acad. Press, Washington, DC.

NRC. 1956. Composition of Concentrate By-Products. Natl. Acad. Press, Washington, DC.

NRC. 1958. Composition of Cereal Grains and Forages. Natl. Acad. Press, Washington, DC.

NRC. 1971. Atlas of Nutritional Data on United States and Canadian Feeds. Natl. Acad. Press, Washington, DC.

NRC. 1982. United States-Canadian Tables of Feeds Composition. 3rd ed. Natl. Acad. Press, Washington, DC.

NRC. 1994. Nutrient Requirements of Poultry. 9 rev. ed. Natl. Acad. Press, Washington, DC.

NRC. 2001. Nutrient Requirements of Dairy Cattle. 7th rev. ed. Natl. Acad. Press, Washington, DC.

NRC. 2012. Nutrient Requirements of Swine. 11 rev. ed. Natl. Acad. Press, Washington, DC.

Pond, W. G., D. C. Church, and K. R. Pond. 1995. Basic Animal Nutrition and Feeding. 4th ed. Wiley, New York, NY.

Sauvant, D., J. M. Perez, and G. Tran. 2004. Tables of Composition and Nutritional Value of Feed Materials. Wageningen Academic Publishers, Wageningen, the Netherlands.

Schingoethe, D. J., K. F. Kalscheur, A. R. Hippen, and A. D. Garcia. 2009. Invited review: The use of distillers products in dairy cattle diets. J. Dairy Sci. 92:5802-5813. https://doi.org/10.3168/ jds.2009-2549.

St. Pierre, N. R., and W. R. Harvey. 1986a. Incorporation of uncertainty in composition of feeds into least-cost ration models. 1. Single-chance constrained programming. J. Dairy Sci. 69:3051-3062. https://doi.org/10.3168/jds.S0022-0302(86)80768-8.

St. Pierre, N. R., and W. R. Harvey. 1986b. Incorporation of uncertainty in composition of feeds into least-cost ration models. 2. Joint-chance constrained programming. J. Dairy Sci. 69:30633073. https://doi.org/10.3168/jds.S0022-0302(86)80769-X.

St. Pierre, N. R., and W. R. Harvey. 1986c. Uncertainty in composition of ingredients and optimal rate of success for a maximum profit total mixed ration. J. Dairy Sci. 69:3074-3086. https://doi .org/10.3168/jds.S0022-0302(86)80770-6.

St-Pierre, N. R., and W. P. Weiss. 2015. Partitioning variation in nutrient composition data of common feeds and mixed diets on commercial dairy farms. J. Dairy Sci. 98:5004-5015. https://doi .org/10.3168/jds.2015-9431.

Sukhija, P. S., and D. L. Palmquist. 1988. Rapid method for determination of total fatty acid content and composition of feedstuffs and feces. J. Agric. Food Chem. 36:1202-1206. https://doi.org/10 $.1021 / \mathrm{jf00084a019}$

Tedeschi, L. O., W. Chalupa, E. Janczewski, D. G. Fox, C. Sniffen, R. Munson, P. J. Kononoff, and R. Boston. 2008. Evaluation and application of the CPM Dairy Nutrition model. J. Agric. Sci. 146:171-182. https://doi.org/10.1017/S0021859607007587.

Thornton, P. K. 2010. Livestock production: Recent trends, future prospects. Philos. Trans. R. Soc. Lond. B Biol. Sci. 365:2853-2867. https://doi.org/10.1098/rstb.2010.0134.

Van Soest, P. J. 1963. Use of detergents in the analysis of fibrous feeds. II. A rapid method for the determination of fiber and lignin. J. AOAC Int. 46:829-835.

Yoder, P. S., N. R. St-Pierre, and W. P. Weiss. 2014. A statistical filtering procedure to improve the accuracy of estimating population parameters in feed composition databases. J. Dairy Sci. 97:56455656. https://doi.org/10.3168/jds.2013-7724.

$[$ REMOVED IF = FIELD $]$ Yu, P. 2005. Applications of hierarchical cluster analysis (CLA) and principal component analysis (PCA) in feed structure and feed molecular chemistry research, using synchrotron-based Fourier transform infrared (FTIR) microspectroscopy. J. Agric. Food Chem. 53:7115-7127. https://doi.org/10 $.1021 /$ jf050959b.

\section{ORCIDS}

H. Tran (®) https://orcid.org/0000-0002-4342-6752

M. B. Hall ৫ https://orcid.org/0000-0002-5460-3208

W. P. Weiss ํ https://orcid.org/0000-0003-3506-4672

P. J. Kononoff $\odot$ https://orcid.org/0000-0001-6069-2174 